\title{
Towards optimum energy performance measures for existing hotels in Egypt
}

\author{
A. Aladassy ${ }^{1}$, G. Mosaad ${ }^{1} \&$ K. Tarabieh ${ }^{2}$ \\ ${ }^{1}$ Department of Architectural Engineering and Environmental Design, \\ AAST, Egypt \\ ${ }^{2}$ The American University in Cairo, Egypt
}

\begin{abstract}
Energy efficiency and renewable energy hold the key to sustainable energy and sustainable tourism development and is the key for energy balance in the hospitality sector of Egypt. Energy cut-offs due to demand exceeding supply in 2014 caused a decline in hotels' revenue of more than $20 \%$. Moreover, electricity prices increased in 2014 by $40 \%$ as a step towards the total removal of electricity subsidies during the following 5 years, representing a threat to the future of the hospitality sector in Egypt. As a result, the hospitality sector in Egypt requires a set of energy efficiency strategies in addition to the diversification of energy supply coupled with continuous and stable prices of other alternatives such as renewable resources. This research proposes a set of strategies that can help the private hospitality sector in Egypt with the proper scenario in utilizing energy resources more efficiently and to integrate renewable energy resources within the existing hotels. A literature review was conducted to define the hospitality sector of Egypt, energy requirements and the market potential of both energy efficiency and renewable energy opportunities focusing on the city of Sharm El Sheikh. The research describes the needed measures that could be used to advance energy efficiency initiatives in the existing hotels of Egypt. Using case studies in the city of Sharm El Sheikh, the research conducted an in depth analysis on different examples, and applied the resulting guidelines on a case study hotel in the same city. The outcome of the research concludes the most effective measures which will eventually help the hotel industry in Egypt to achieve optimum, continuous and stable energy performance in addition to a reduction in carbon emissions.

Keywords: sustainable tourism, sustainable energy, energy efficiency, renewable energy, developing existing hotels, Egyptian tourism.
\end{abstract}




\section{Introduction}

"What we need to do is really improve energy efficiency standards, develop in full scale renewable and alternative energy and use the one resource we have in abundance, our creativity [1]."

The growth of carbon dioxide concentrations in the earth's atmosphere with attendant global warming from fossil fuel combustion to produce energy makes the transition to non-carbon energy resources and energy efficiency more urgent. Since buildings contribute about $40 \%$ of the world's carbon dioxide emissions the focus of carbon reduction policies, programs, and actions must necessarily be in the build environment [2].

Egypt faces a major challenge in providing a sufficient amount of electricity. Primary non-renewable energy resources contribute to $90 \%$ of the total energy resources needed for generating electricity in Egypt [3]. While energy cut-offs due to demand exceeding supply in 2014 caused a decline in hotels' revenue of more than $20 \%$, the running costs of generators and maintenance work increased by $15 \%$. On the other hand, electricity prices increased in 2014 by $40 \%$ as a step towards the total removal of subsidies for electricity during the next 5 years [4].

Moreover, energy efficiency practices can help reduce costs, open up new markets, and improve the company reputation. Beyond savings in energy expenses, the real gains in energy efficient transformation lie in the "soft" benefits such as improvements in health, comfort, productivity of hotels' occupants, enhanced marketing and public relations, risk mitigation, improved recruitment, and greater employee morale while promoting environmental restoration, economic prosperity, social welfare, and equity [2].

\section{The hospitality sector of Egypt}

In Egypt, recreational tourism has grown rapidly over the past 30 years in particular locations such as Sharm El Sheikh, Hurghada, Safaga, Taba, Marsa Alam and other places in the Sinai and Red Sea areas, reaching from 274 hotels with 22,756 rooms in 1984 to 945 hotels with 178,799 rooms in 2014 with different categories (fig. 1). 23\% of the hotels in Egypt are categorized 3* representing $20 \%$ of the total room number, while $5^{*}$ hotels represent $12 \%$ of hotels in Egypt with 35\% of the total room number. European countries are the main source of tourism in Egypt with about $74.2 \%$ followed by the Middle East countries with 13.6\%. However, after the "Egyptian revolution" in 2011, the number of visitors has decreased notably causing an economical crisis in the hospitality sector in Egypt [5]. Tourism in Egypt is recognized to be one of the largest contributors to Egypt's economic growth, representing a second source of national income with $11.5 \%$ of GDP, offering $19.5 \%$ of the foreign currency, and offering $12.6 \%$ of the total working labor [6].

\subsection{The City of Sharm El Sheikh}

Lying at the southern flank of the Peninsula where both Aqaba and Suez gulfs meet with the Red Sea; the city of Sharm El Sheikh stands as the biggest and 


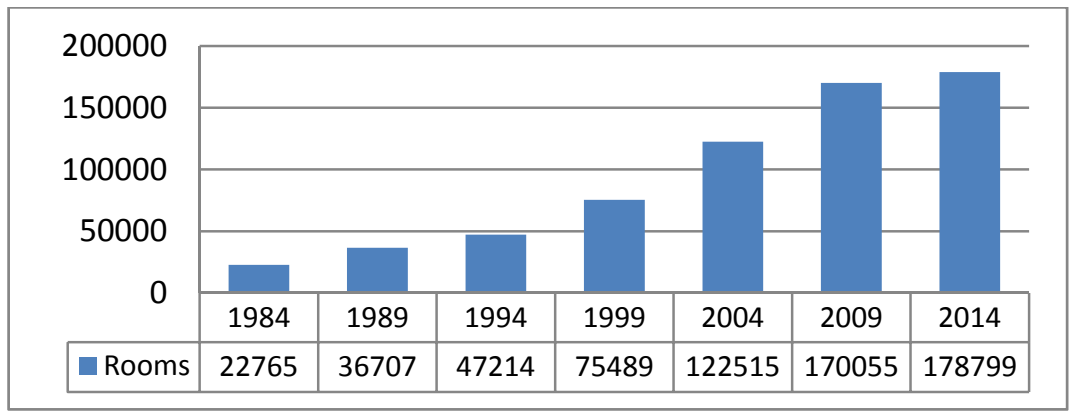

Figure 1: Egypt's hospitality room capacity in the past 30 years.

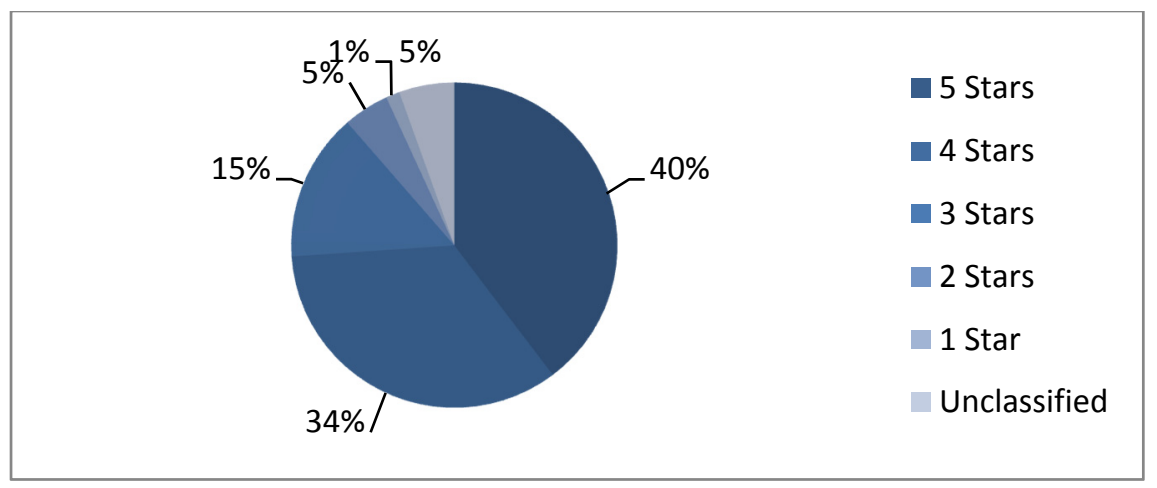

Figure 2: South Sinai's category segmentation.

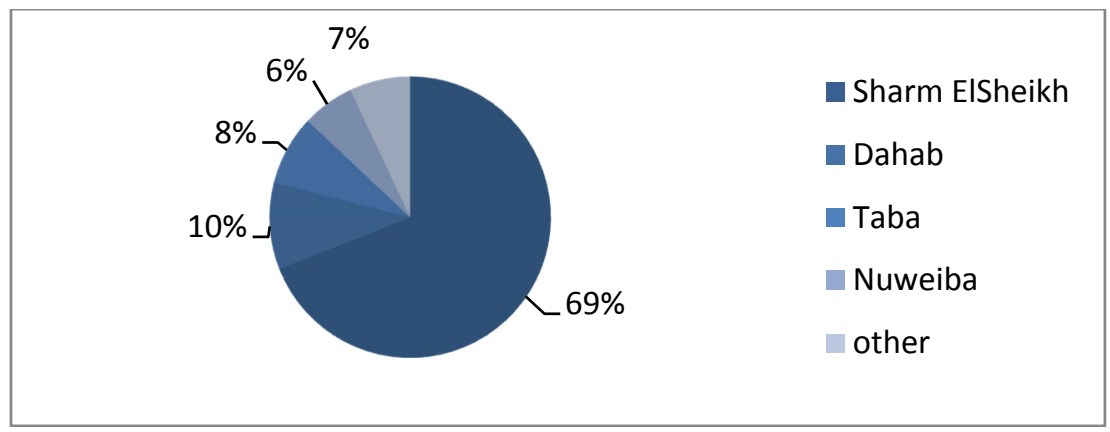

Figure 3: South Sinai hotel segmentation.

most important city of the South Sinai Government, considered as the most famous seaside resort in the area with all room categories (fig. 2). South Sinai has 283 hotels that can be found in South Sinai concentrated mainly in the city of Sharm El Sheikh with 194 hotels in Sharm El Sheikh, 30 hotels in Dahab, 23 in Taba and 17 in Nuweiba, with a total capacity of 62,796 rooms which represents more than 35\% of Egypt's total room number [4] (fig. 3). 
South Sinai has an arid desert climate, the winter temperature is warm and the summer weather is very hot and dry with low humidity, making high temperatures a lot more bearable. The temperature during the day can be about $40^{\circ} \mathrm{C}$ and decrease during the night time to about $30^{\circ} \mathrm{C} \mathrm{[7]} \mathrm{(as} \mathrm{shown} \mathrm{in} \mathrm{fig.} \mathrm{4).}$
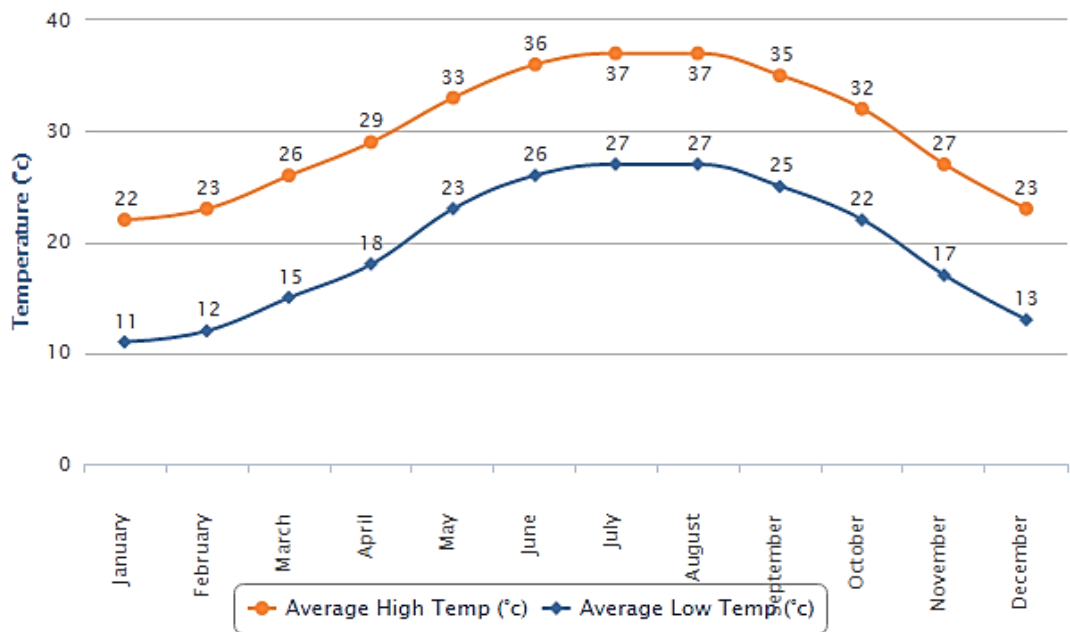

Figure 4: Average temperature at South Sinai Government.

\section{Energy in the hospitality sector of Egypt}

Egypt faces a major challenge in providing a sufficient amount of electricity. Primary non-renewable energy resources contribute to $90 \%$ of the total energy resources needed for generating electricity in Egypt. Energy demand in Egypt is projected to grow at an average annual growth rate of $2.6 \%$ [8]. One of the critical aspects of the energy sector in Egypt is the high level of subsidies in energy prices, representing a substantial drain on Egypt's budget; for the electricity at the commercial hotel sector subsidies in 2010 are over $50 \%$ for electricity, $75 \%$ in natural gas and over $90 \%$ in liquid petroleum gases. If energy subsidies are calculated on the basis of full economic cost, the resulting number will reach 140 billion EGP, equivalent to about 12\% of GDP [9]. Energy subsidies amount to about $75 \%$ of all subsidies in Egypt and approximately $21 \%$ of the country's budget [10].

\section{Energy efficiency and renewable energy measures}

One way to foster energy efficiency in the hotel sector in Egypt is to promote the most adaptable, practical and cost-effective solutions to hotels in order to improve their energy efficiency and integrate renewable energy. The aim of this section is to provide a review of energy efficiency and renewable energy 
measures that are available to hotels in Egypt. It is intended to be a guide for hotel managers/owners, with an overview of several measures which can be selected individually for implementation in existing Egyptian hotels. A table with the energy efficiency and renewable energy measures is concluded at the end of this section that could be used in Egypt generally and Sharm El Sheikh specifically.

\subsection{Building characteristics}

A building's envelope should increase energy efficiency performance while offering comfort to users using environmental architecture designs and passive cooling methods (fig. 5). When retrofitting a building's envelope to get high energy efficiency performance, the following points should be considered [11].

\subsubsection{Envelope}

A building's envelope should prevent air infiltration to internal cooled spaces to avoid increasing the indoor air temperature. Air leaks from windows and doors, cracks, gaps between connections of AC pipes, lights, sanitation and electrical fixations should be avoided and blocked between cooled spaces and non-cooled spaces or outdoor temperature.

\subsubsection{Thermal resistance}

Thermal resistance on a building's envelope should be calculated on each $1 \mathrm{~m}^{2}$ of the elevation with the consideration of both indoor and outdoor temperatures and the structure material including bricks, stones, concrete, plaster, cladding, sand, floor tiles, insulation and all other materials used in the structure.

\subsubsection{Thermal insulation}

Thermal insulation should be used if needed and it should fill any heat leakage especially in connection between walls and ceilings.

\subsubsection{External openings}

External openings, openings orientation and openings ratio to the walls ratio should be calculated and modified to control indoor air temperature and natural ventilation.

\subsubsection{Shading devices}

Fixed or movable shading devices and louvers could be used to control the indoor air temperature.

\subsubsection{Glazing}

Glazing should be designed and modified depending on a building's external climate to control the indoor air temperature. If there is a conflict between natural light and indoor air temperature then specific types of glass that pass natural light and block heat should be considered. For example, adding multiple layers of glazing to the present windows for improving the hotel energy performance. Simple energy efficiency could be implemented in the facades of a running hotel without affecting its operation and with interesting results, such as installing solar films in windows. 


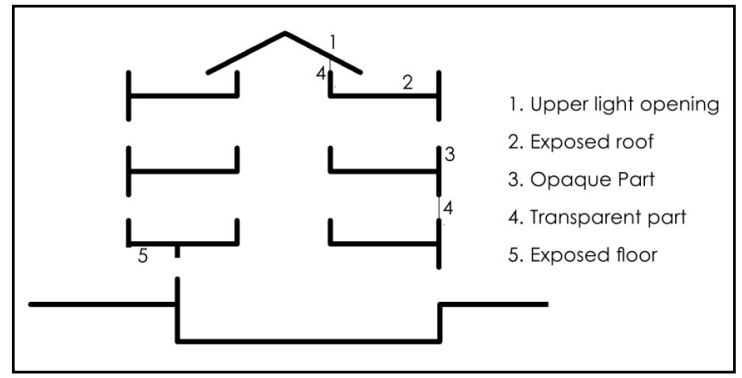

Figure 5: Building envelope elements.

\subsection{Cooling systems}

\subsubsection{Natural ventilation}

Natural indoor air circulation removes indoor pollution; affording indoor natural circulation is a necessity. The three main roles of natural ventilation are indoor thermal comfort, structure cooling and healthy indoor air quality [11].

\subsubsection{Switching from individual split units to centralized air cooling systems}

There is an opportunity for switching to centralized cooling systems when the cycle life is completed, due to higher coefficient of performance (COP) ratios of centralized equipment and the lower equivalent full load hours (EFLH) of centralized equipment versus individual units [5].

\subsubsection{Replacement of air cooled chillers to absorption chillers}

In areas that are being connected to the natural gas grid, there is a chance of saving costs for producing the cooling demand through absorption chillers switching from electricity to a cheaper fuel, such as natural gas.

\subsubsection{Cooling efficiently}

Installing automatic systems (key cards), turning off air conditioning and lights when guests leave their rooms in guest rooms. Surfaces of a cooling exchanger of the air conditioner are cleaned every three months. Electricity of air conditioning units is assured by shading the air conditioning condensers at $35 \%$ [12].

\subsection{Water heating systems}

\subsubsection{Solar water heaters}

Solar water heaters (SWH) are one of the most relevant energy efficiency measures for the areas due to the high irradiation factor of $5.5 \mathrm{kWh} / \mathrm{m}^{2} /$ day for much of the year. Changing central diesel boilers with solar water heating (SWH) designed for covering the heat demand of hot water for swimming pools in winter and, additionally, producing hot domestic water for the guest rooms [5]. 


\subsubsection{Water conservation}

To reduce water demand, the hotels must have efficient equipment; another way would be to educate both in-house staff and customers [5].

\subsubsection{Waste heat recovery systems}

Heat recovery systems are mainly dependent on waste energy (rejected heat to the atmosphere) by the different thermodynamic cycles applied in the hotels [5].

\subsection{Lighting systems}

\subsubsection{Natural lighting}

Natural lighting is considered to be the most important method to improve energy efficient performance and reduce energy consumption in commercial buildings since most energy consumption in commercial buildings is through artificial lights and cooling the spaces with heat resulting from artificial lights [11].

\subsubsection{Artificial lighting}

Artificial lighting is considered to be one of the major energy consumption elements in Egypt, and causes an additional load on cooling systems. Artificial lighting should have low thermal emissions; more energy efficient and low cost [11].

\subsubsection{Automatic lighting systems}

Automatic light systems include a time control system, occupancy sensors system and light intensity control system [11].

\subsubsection{PV lighting}

The main opportunity of PV application is considered to serve the demand of the landscape and both the indoor and outdoor lighting system due to the high irradiation factor in Egypt above $5.5 \mathrm{kWh} / \mathrm{m}^{2} /$ day [5].

\subsection{Electrical power systems}

\subsubsection{Power factor ratio}

Improving energy efficiency in electrical fittings and equipment in commercial buildings reduces electrical losses through increasing cables' diameter, increasing efficiency in electrical convertors and motors and through balancing electrical loads. All electrical equipment including motors, AC units, light units and refrigerators should have a power factor (ratio between effective and apparent power) from 0.85 to 0.89 [11].

\subsubsection{Adding pressure exchangers to the desalination plants}

This specific energy index could be reduced by $50 \%$ by using a pressure exchanger unit that recovers the pressure of disposed brine to the sea water introduced to the membranes. Therefore, it is highly recommended to introduce this concept to all installed RO plants since minor modifications are required for the process [5]. 


\subsubsection{Building energy management system}

A building energy management system (BEMS) is a computer-based system that automatically monitors and controls a range of hotel services, including air conditioning, ventilation, heating, lighting and other energy consumers within the building or sometimes even groups of buildings [5].

\subsubsection{Fuel switching to natural gas}

Hotels in Sharm El Sheikh are being connected to the natural gas grid as it is being expanded by the gas utility. Most of the hotels are utilizing diesel in their combustion systems. The benefits in this energy conservation measure are clear: less greenhouse gas emissions, combustion efficiency improvement, and removal for risks in fuel oil loading, transportation and unloading [5].

\subsubsection{Cogeneration plants for natural gas grid connected areas}

Cogeneration (or combined heat and power, CHP) is the simultaneous production of electricity and thermal energy from the same fuel source [5] (fig. 6).

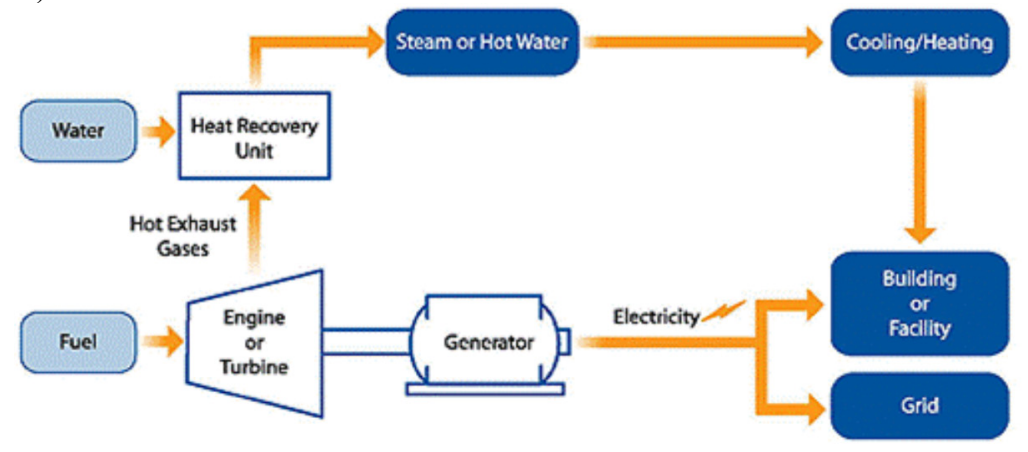

Figure 6: Cogeneration plants.

\section{Conclusion}

The desirable comfort needed in the hospitality sector can be achieved with lower energy consumption using energy efficient strategies and energy monitoring systems. Lack of energy efficient strategies and renewable energy resources are obvious in the hospitality sector in Egypt. Meanwhile, the technologies along with the high primarily and debit capital needed to achieve and afford these strategies are challenges which need creative solutions and funding methods to make it all possible. The possible energy efficient and renewable energy measures available to Egyptian hotels have been classified into five different groups, which are building's envelope, cooling systems, water heating systems, lighting systems and electrical power systems. Each of these groups consists of different detailed measures, further information was provided for each measure concerning potential energy savings, estimated cost and the category it belongs to; specified as architectural, mechanical, electrical or other, as shown in the concluded table below (Table 1). 


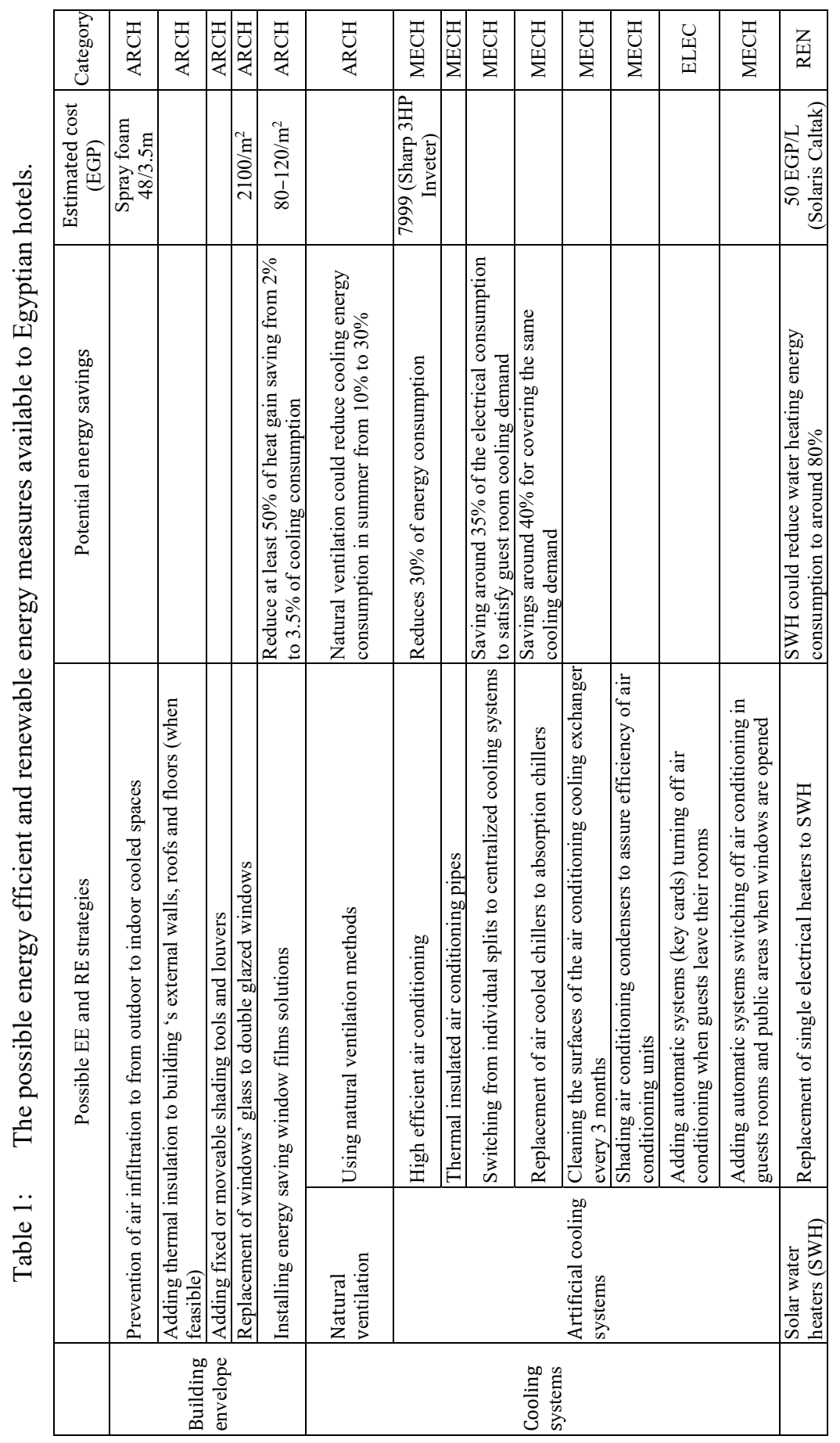




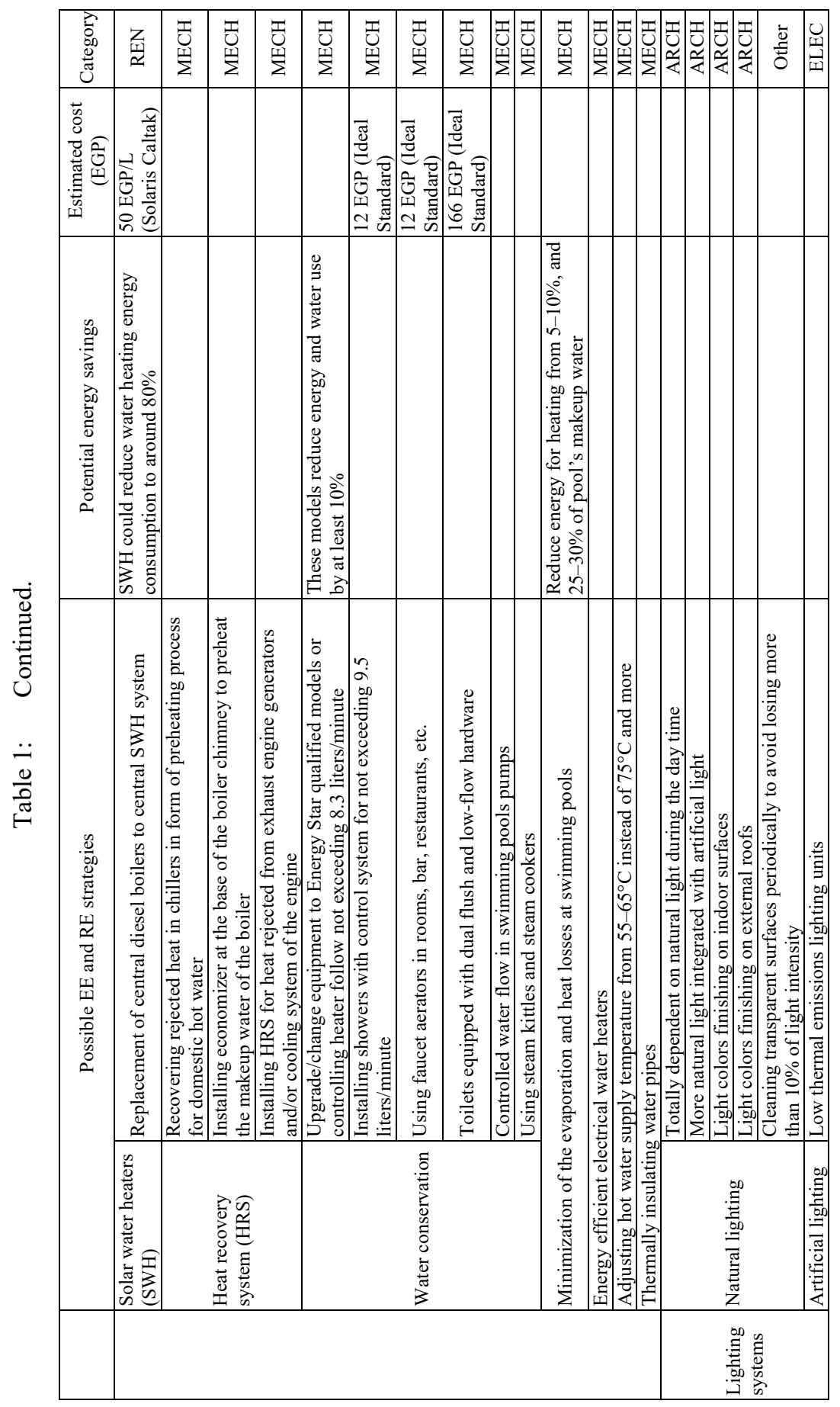




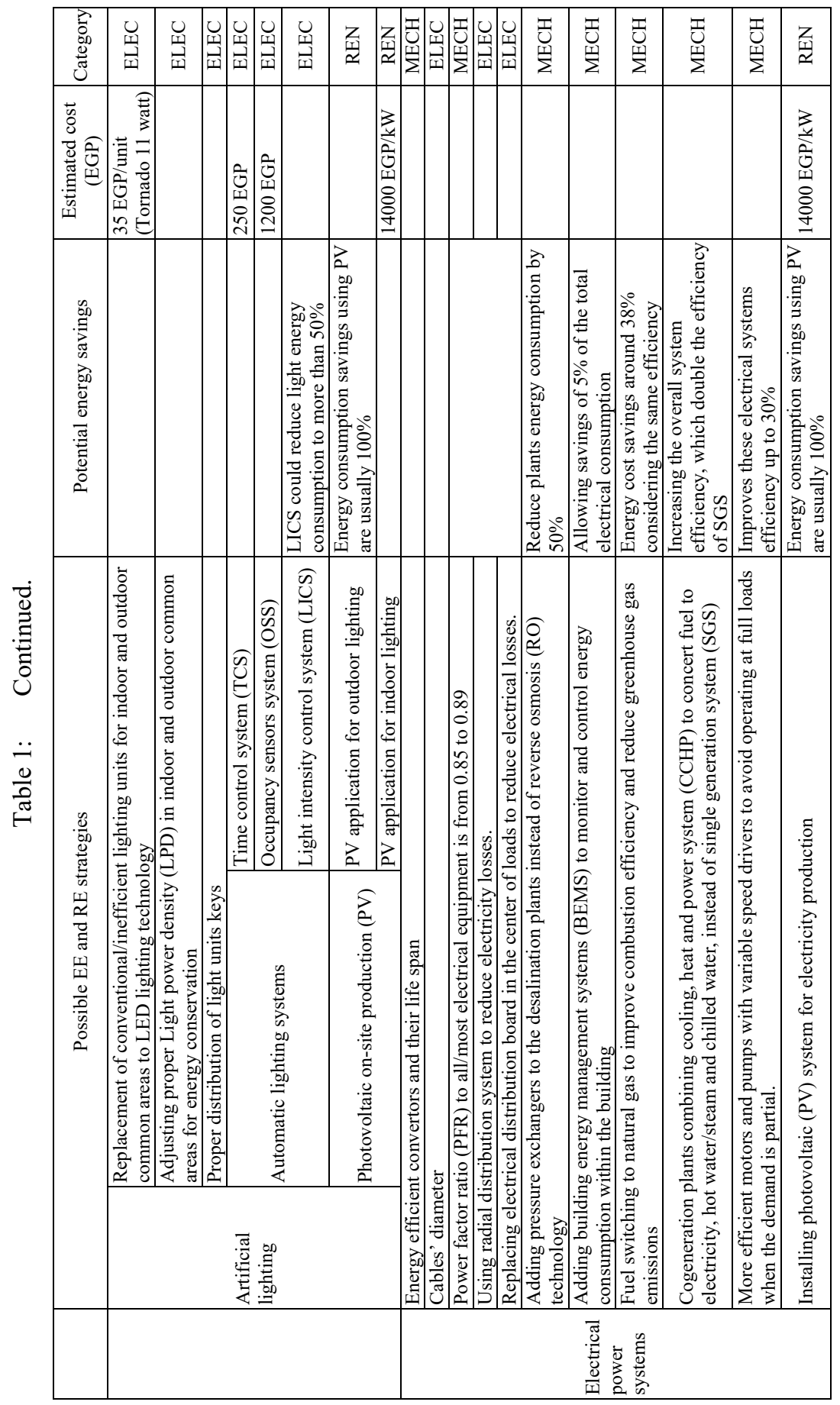




\section{References}

[1] G. Beck, Grid Parity: The Art of Financing Renewable Energy Projects in the US, Fairmont Press, May, 2014.

[2] J. Yudelson, Greening Existing Buildings, California: McGraw-Hill Education, 2009.

[3] Ministry of Electricity and Energy, 2013 [online]. Available: http://www.moee.gov.eg [accessed 20 May 2015].

[4] Egyptian Hotel Association, Egyptian Hotel Association, 2013 [online]. Available: http://www.egyptianhotels.org/ [accessed 2014].

[5] AF-Mercados EMI, "Sustainable Energy Support for Built Environment Projects," European Bank for Reconstruction \& Development, Spain, September 2013.

[6] Tourism Development Authority, "Tourism Development Authority," Tourism Development Authority, 2012. [online]. Available: http://www.tda.gov.eg/ [accessed 2015].

[7] World Weather Online, "World Weather Online," [online]. Available: http://www.worldweatheronline.com/ [accessed 2014].

[8] International Energy Agency, OECD/IEA [online]. Available: http://www.iea.org/ [accessed 2014].

[9] The World Bank, "Data," The World Bank, 2016 [online]. Available: http://data.worldbank.org/country/egypt-arab-republic [accessed 2015].

[10] African Development Bank Group, "Egypt Economic Outlook," 2016 [online]. Available: http://www.afdb.org /en/countries/north-africa/egypt/ egypt-economic-outlook/ [accessed 2015].

[11] The Preparing Committee of the Egyptian Code for Energy Efficiency in Buildings, The Egyptian Code for Energy Efficiency in Buildings, Cairo: Housing \& Building National Research Center, 2005.

[12] A. C. E. Barbara Fritz, How to Become a Green Star Hotel, Egypt: The Green Star Hotel Initiative, July, 2008. 